\title{
UJI BANDING LIMBAH CAIR IKAN, AZOLLA DAN LIMBAH KULIT PISANG SEBAGAI NUTRISI TAMBAHAN UNTUK KUALITAS PRODUKSI TANAMAN CABAI RAWIT (Capsicum frutencens $L$.)
}

\author{
N. F. Rochmana ${ }^{1}$ dan Ngadiani $^{2}$ \\ ${ }^{1}$ Mahasiswa Prodi Biologi F.MIPA Universitas PGRI Adi Buana Surabaya \\ ${ }^{2}$ Staff pengajar Prodi Biologi F.MIPA Universitas PGRI Adi Buana Surabaya \\ Email: nfaizal1816@gmail.com
}

\begin{abstract}
ABSTRACK
Household waste in the form of fish waste, azolla pinnata, and banana peel waste is a waste that has not been utilized optimally. The potential waste can be utilized as a raw material of organic nutrients with macro elements more complete than an-organic nutrients. Giving various variations of organic liquid nutrients can be used to chili (Capsicum frutencens $L$.). This study aims to determine the effect of different variations of organic liquid nutrient on the quality of chili production (Capsicum frutencens L.). The type of this research is quantitative research with experimental method using Completely Randomized Design consisting of 3 treatments 6 replications, so that there are 18 experimental units adn placed randomly was fish waste $20 \%\left(\mathrm{~N}_{1}\right), 20 \%$ Azolla Pinnata $\left(\mathrm{N}_{2}\right)$, and banana peel waste $20 \%$ (N3). Observations were made on three parameters of production quality is colour, taste, and wet weight. Technical of data analysis using One-way ANOVA with significance level of 0,05. One-way ANOVA test results on the quality of chili production is $\mathrm{P}>0,05$. One-way ANOVA test results showed no signification on the quality of chili production (Capsicum frutencens L.).
\end{abstract}

Keywords: Organic Liquid Nutrition, Liquid Waste Fish, Azolla Pinnata, Banana Peel Waste, Quality Productions of Plants, Chili.

\section{PENDAHULUAN}

Cabai rawit

(Capsicum

frutescens L.) merupakan salah satu komoditas sayuran

yang keberadaannya tidak dapat ditinggalkan oleh masyarakat Indonesia dalam kehidupan seharihari. Cabai rawit digunakan sebagai bahan bumbu dapur, bahan utama industri saus, industri bubuk cabai, industri mie instan, sampai industri farmasi. Kebutuhan cabai rawit cukup tinggi yaitu sekitar 4kg/kapita/tahun (Warisno, 2010). Budidaya tanaman cabai di Indonesia sangat erat dengan penggunaan pupuk anorganik yang berlebihan. Penggunaan pupuk anorganik secara terus menerus tanpa diimbangi oleh pemupukan organik akan memberi dampak buruk pada tanah sehingga kandungan bahan organik dalam tanah dan produktivitas lahan menurun disertai kehilangan unsur hara makro dan mikro yang tersedia 
dalam tanah (Sambodo $d k k$, 2014).

Upaya yang dapat dilakukan untuk menangani hal itu adalah dengan cara pemeliharaan tanaman berupa penggunaan pupuk organik, baik itu berupa cairan maupun kompos. Selama ini kompos yang dihasilkan dari limbah padat sangat banyak, padahal pupuk cair lebih praktis digunakan, proses pembuatanya relative mudah, dan biaya pembuatan yang dikeluarkan juga tidak terlalu besar (Hadisuwito, 2007).

Pupuk organik cair adalah salah satu jenis pupuk yang dapat digunakan untuk meningkatkan produktivitas komoditas pertanian sehingga penggunaan pupuk organik cair diharapkan dapat memperbaiki kesuburan tanah sekaligus menyediakan unsur hara yang dibutuhkan oleh komoditas pertanian.

Di Indonesia, limbah cair ikan belum dimanfaatkan secara maksimal. Limbah cair ikan yang terbuang ternyata masih dapat dimanfaatkan sebagai bahan baku pupuk organik dengan kandungan unsur- unsur makro lebih lengkap dibandingkan dengan pupuk anorganik. Kandungan unsur makro dalam pupuk biasa terbatas, tidak mencukupi untuk kebutuhan tanaman. Dengan begitu harus dilengkapi dengan penambahan unsur lain agar kandungan nitrogen, fosfor, dan kaliumnya sesuai dengan jumlah yang dibutuhkan. Pupuk organik cair mengandung unsur hara makro dan mikro essensial yang cukup tinggi seperti Natrium (N), Phospor (P), Kalium (K), Calsium (Ca), Magnesium (Mg), Sulfur (S), Ferrum (Fe), Zincum (Zn), Cuprum $(\mathrm{Cu}), \quad$ Mangan $(\mathrm{Mn})$, Chlor (Cl), Boron (Bo), Molibdenum (Mo), dan bahan organik.

\section{Azolla Pinnata adalah} tanaman paku yang dapat dimanfaatkan menjadi pupuk organik yang diaplikasikan dalam bentuk azolla segar maupun kompos. Tanaman azolla mempunyai kandungan unsur hara, terutama nitrogen yang sangat tinggi. Oleh karena itu, pemanfaatan azolla disamping menjaga keseimbangan hara dalam tanah. Azolla dapat membantu memperbaiki keadaan fisik, kimia, serta biologi tanah sehingga sangat bermanfaat bagi pertumbuhan tanaman. Keadaan fisik tanah yang diperbaiki azolla seperti stabilitas agregat, struktur, dan porositas tanah karena kerapatan massa tanah menjadi berkurang. Ditinjau dari segi kimia tanah, azolla dapat memperkaya unsur hara makro dan mikro dalam tanah. Sedangkan dari segi biologi tanah, azolla dapat meningkatkan aktivitas mikroba tanah dan menghambat pertumbuhan gulma. Ini disebabkan azolla akan cepat tumbuh dan berkembang menutupi permukaan air sehingga cahaya dan air yang diperlukan dalam proses fotosintesis gulma menjadi terganggu (Arifin, 1996). 
Kulit pisang yang selama ini kurang dimanfaatkan oleh masyarakat dapat dijadikan pupuk cair. Kulit Pisang mengandung unsure $\mathrm{P}, \mathrm{K}, \mathrm{Ca}, \mathrm{Mg}, \mathrm{Na}, \mathrm{Zn}$ masing-masing berfungsi untuk pertumbuhan dan perkembangan tanaman yang berdampak pada jumlah produksi yang maksimal (Soeryoko hery, 2011). Penelitian Hanum (2012) diperoleh hasil kadar air pektin yang dihasilkan kulit buah pisang berkisar 9,52-11,88\% . Batas maksimum nilai kadar air yang diizinkan yaitu $12 \%$.

Informasi dan laporan hasil penelitian sebagai pembuktian ilmiah mengenai potensi limbah rumah tangga sebagai nutrisi organik cair yang berpengaruh terhadap kualitas tanaman belum banyak dipublikasikan. Penelitian ini bertujuan untuk membuktikan efek limbah rumah tangga dalam kualitas produksi terhadap warna, rasa dan berat basah pada tanaman cabai rawit (Capsicum frutencens $L$.).

\section{Materi dan Metode Penelitian Metode Penelitian}

Penelitian ini dilaksanakan pada bulan Februari-Mei 2017 dengan metode eksperimental di Desa Sadang RT/RW 002/001, Taman-Sidoarjo, dengan metode Rancangan Acak Lengkap (RAL) yang terdiri dari 3 perlakuan dan 6 ulangan sehingga diperoleh 18 unit polybag eksperimental.

\section{Alat dan Bahan Penelitian}

Alat yang digunakan adalah drum, kertas $\mathrm{pH}$ indikator, wadah plastik, kompor gas, panci, polybag 30x30 sebanyak 18 buah, kertas label, cetok, gelas ukur, filter, pengaduk larutan, blender, kain saring, oven, timbangan, media tanam arang sekam, kompos, dan sprayer.

Bahan yang digunakan adalah benih tanaman cabai rawit (Capsicum frutencens L.) var. hibrida, limbah ikan, azolla pinnata, limbah kulit pisang, dedak, gula, air kelapa, dan EM-4 (bioaktivator).

\section{PROSEDUR PENELITIAN}

\section{Pembuatan Nutrisi Organik}

Cair

Melarutkan $100 \mathrm{ml}$ EM-4, gula 100 gr, dalam 1 liter air kemudian didiamkan selama 5 hari. 500 gr limbah ikan, dedak 1000 gr, air kelapa $500 \mathrm{ml}$, dan air sebanyak 2 liter dicampur dan dihaluskan. Kemudian ditambahkan larutan EM4 dan difermentasikan selama 7 hari. $1 \mathrm{~kg}$ azolla pinnata akan direbus dengan 1 liter air selama 30 menit dan disaring. Filtrat diambil sebagai konsentrasi $100 \%$ dari filtrat azolla. Kemudian didinginkan pada suhu antara $0-4^{\circ} \mathrm{C}$. Kulit pisang seberat 1 $\mathrm{kg}$ dicincang, kemudian larutkan $100 \mathrm{ml} \mathrm{EM-4} \mathrm{(bioaktivator),} \mathrm{air} 1$ liter, gula pasir 100 gr. Campur cacahan kulit pisang dengan larutan tersebut, tambahkan 100 gr dedak, aduk rata kemudian fermentasi selama 7 hari. Nutrisi organik cair siap digunakan. 


\section{Persemaian Cabai Rawit}

Biji yang siap digunakan, ditaburkan pada media tanah selama 25 hari hingga benih siap dipindahkan ke media polybag.

\section{Pengolahan Lahan}

Mencampurkan arang sekam dan kompos, dibiarkan selama 7 hari untuk mentralisir $\mathrm{pH}$ yang terdapat pada media tanam.

\section{Penanaman}

Bibit yang sudah siap tanam, dipindahkan ke media polybag untuk diberi perlakuan nutrisi organik cair.

\section{Perawatan dan Pemeliharaan}

Mengatur kadar air pada media tanam agar selalu stabil dengan menyiramnya $2 \mathrm{x}$ sehari. Sedangkan nutrisi yang diaplikasikan meliputi Limbah cair ikan 20\% (N), Azolla Pinnata 20\% $\left(\mathrm{N}_{1}\right)$, dan Limbah Kulit Pisang 20\% $\left(\mathrm{N}_{2}\right)$ dilakukan 1 minggu setelah persemaian pindah ke polybag. Selanjutnya dilakukan setiap 1 minggu sekali hingga tanaman siap dipanen pada umur 100 HST.

\section{Perolehan data}

Data diperoleh dari respon para panelis terhadap sifat organoleptik cabai rawit yang meliputi warna dan rasa. Selanjutnya menimbang berat basah cabai rawit untuk memperoleh data berat pasca panen.

\section{Metode Analisa Data}

Data yang diperoleh disajikan dalam bentuk tabel dan grafik. Adanya pengaruh perbandingan penggunaan limbah digunakan analisis statistic menggunakan analisis varian One-way ANOVA dengan bantuan software SPSS Statistics 21.

\section{HASIL PENELITIAN}

Berdasarkan data yang diperoleh, selanjutnya data dianalisis untuk memperoleh jawaban yang akurat atas bentuk permasalahan serta suatu kebenaran hipotesa. Penelitian mengenai perbandingan variasi nutrisi organik cair dari limbah ikan, azolla dan limbah kulit pisang berpengaruh terhadap kualitas produksi tanaman cabai rawit (Capsicum frutencens L.) menghasilkan data penelitian berupa warna, rasa dan berat basah pasca panen yang diperoleh pada waktu tanaman berumur 100 HST. 


\section{Warna Cabai Rawit (Capsicum frutencens $L$. )}

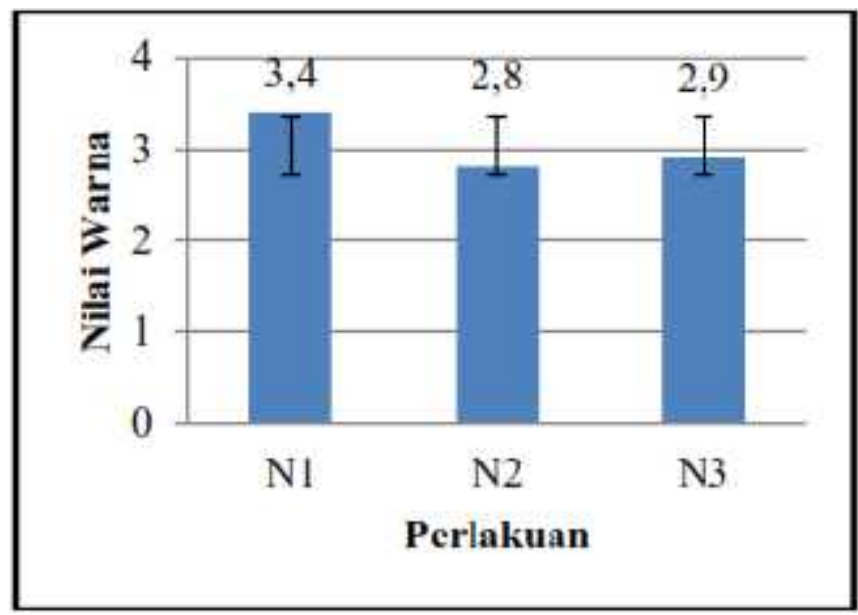

Gambar 1. Diagram rerata nilai warna cabai rawit (Capsicum frutencens L.)

Berdasarkan hasil Uji dengan perlakuan $\mathrm{N}_{3}$. Dari hasil Parametik One-way ANOVA dapat penelitian masing-masing perlakuan diketahui bahwa antara perlakuan tidak signifikan berpengaruh $\mathrm{N}_{1}$ berbeda nyata dengan perlakuan terhadap kualiatas warna cabai rawit $\mathrm{N}_{2}$, namun tidak berbeda nyata (Capsicumfrutencens $L$.).

\section{Rasa Cabai Rawit (Capsicum frutencens L.)}

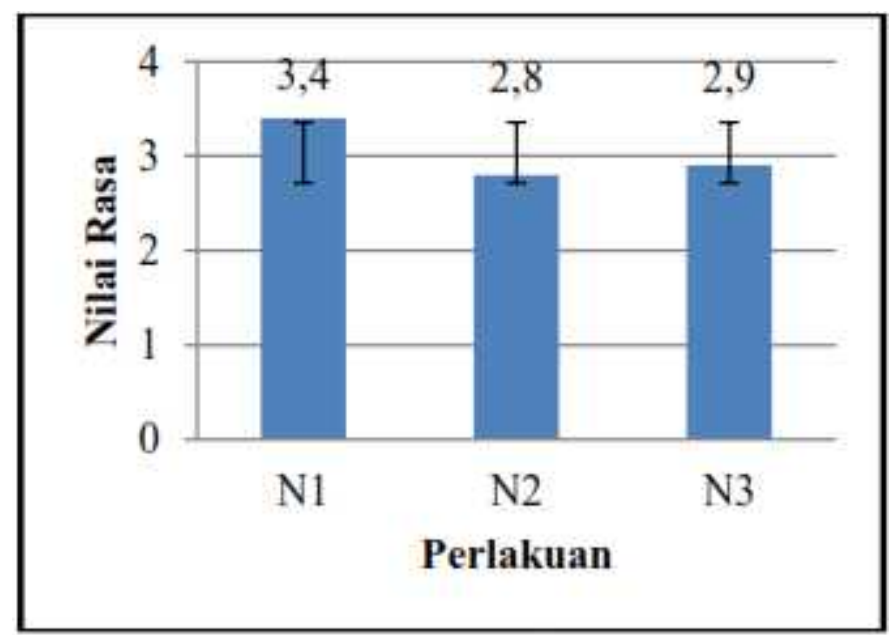

Gambar 2. Diagram rerata nilai rasa cabai rawit (Capsicum frutencens $L$.) 
Berdasarkan hasil Uji Parametik One-way ANOVA dapat diketahui bahwa antara perlakuan $\mathrm{N}_{1}$ berbeda nyata dengan perlakuan $\mathrm{N}_{2}$, namun tidak berbeda nyata dengan perlakuan $\mathrm{N}_{3}$. Dari hasil penelitian, masing-masing perlakuan tidak signifikan berpengaruh terhadap kualiatas rasa cabai rawit (Capsicum frutencens L.) (P>0,05).

\section{Berat basah pasca panen cabai rawit (Capsicum frutencens $L$.)}

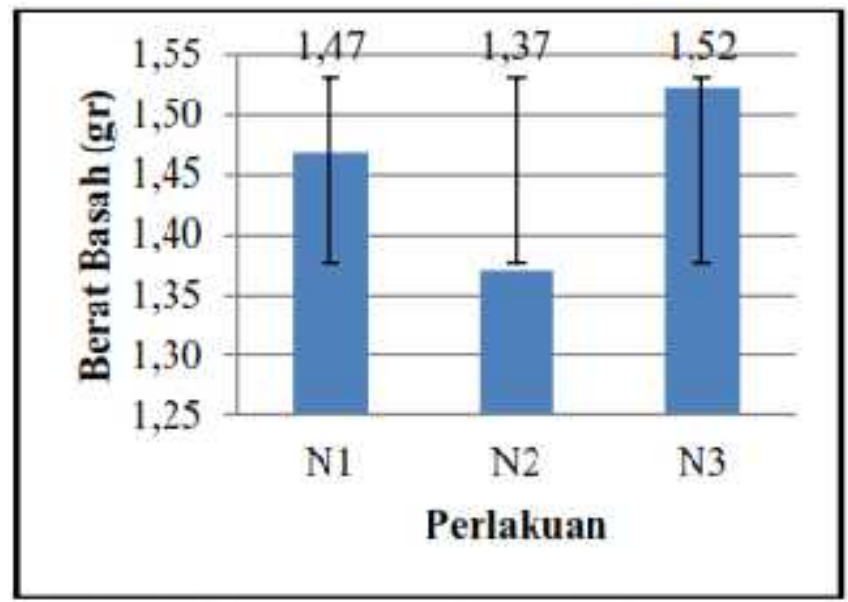

Gambar 3. Diagram rerata berat basah pasca panen cabai rawit (Capsicum frutencens $L$.)

Berdasarkan hasil Uji Parametik One-way ANOVA dapat diketahui bahwa antara perlakuan N1 tidak berbeda nyata dengan perlakuan $\mathrm{N}_{2}$. Perlakuan $\mathrm{N}_{2}$ berbeda nyata dengan perlakuan $\mathrm{N}_{3}$. Dari

\section{PEMBAHASAN}

\section{Kualitas Produksi Cabai Rawit (Capsicum frutencens $L$.)}

Warna merupakan parameter penting yang menentukan kualitas cabai rawit (Capsicum frutencens L.). Pada data secara statistik diketahui perlakuan nutrisi organik cair dari $\mathrm{N}_{1}, \mathrm{~N} 2$ dan $\mathrm{N}_{3}$ tidak berbeda nyata, namun pada penelitian ini pemberian nutrisi hasil penelitian, masing-masing perlakuan tidak signifikan berpengaruh terhadap kualiatas berat basah cabai rawit (Capsicum frutencens $L$. $)(\mathrm{P}>0,05)$.

terbaik didapat pada perlakuan nutrisi organik N1.

Hasil penelitian Fatimatuz Zahro (2015), menunjukkan jeroan ikan memiliki kandungan nutrient kalium (380 mg) dimana kalium berfungsi mempercepat proses asimilasi karohidrat, pertumbuhan akar, batang, daun dan buah. Kekurangan nutrien kalium mengakibatkan bercak-bercak pada 
buah, atau keriput buah dan pada akhirnya buah akan mengering.

Rasa pedas cabai rawit (Capsicum frutencens L.) berasal dari senyawa capsaicin, dimana capsaicin terdapat pada biji, kulit, dan daging buah cabai. Nutrisi organic cair $\mathrm{N}_{2}$ memiliki nilai rasa (pedas) paling rendah, karena rendahnya kandungan unsur kalsium (Ca). Peran unsur Kalsium (Ca) sangat dominan, terutama pada titiktitik tumbuh tanaman seperti pucuk muda dan ujung akar. Kekurangan kalsium menyebabkan pertumbuhan tanaman terhambat dan menurunnya kualitas buah. Kalsium berperan memicu pembentukan biji cabai, jika tanaman cabai kekurangan kalsium (Ca) maka biji dari buah cabai tersebut tidak bernas/kopong sehingga rasa (pedas) yang dihasilkan dari biji cabai sedikit atau bahkan tidak ada.

Dalam penelitian Sriharti (2008), menerangkan bahwa limbah kulit pisang merupakan substansi organik dengan kandungan Nitrogen sebesar $35 \%$ yang berguna sebagai penggembur. Kandungan gizi dalam kulit pisang berpotensi sebagai sumber mikroorganisme lokal karena kandungan gizi dalam kulit pisang dapat digunakan sebagai sumber makanan sehingga mikroba berkembang dengan baik untuk memperbaiki perakaran sehingga mempengaruhi penyerapan hara.

Hasil penelitian Indrasari dan Syukur (2006), menunjukkan bahwa pemberian unsur hara mikro meningkatkan konsentrasi unsur tersebut dalam jaringan tanaman sehingga mampu meningkatkan bobot basah tanaman menjadi lebih tinggi. Selain itu penyerapan air yang tinggi terhadap tanaman cabai rawit (Capsicum frutencens $L$.) yang mempengaruhi berat basah panen sehingga mengakibatkan cabai rawit (Capsicum frutencens L.) cepat membusuk.

\section{KESIMPULAN}

Berdasarkan analisis dan pembahasan data hasil penelitian, dapat disimpulkan bahwa:

1. Pemberian berbagai variasi nutrisi organik cair. Dari limbah ikan, azolla pinnata, dan limbah kulit pisang tidak berpengaruh signifikan terhadap kualitas produksi tanaman cabai rawit (Capsicum frutencens L.).

2. Pemberian nutrisi organik cair dari limbah ikan memberikan kualitas prosuksi terbaik pada warna buah dan rasa (pedas), sedangkan nutrisi organic cair dari limbah kulit pisang mendominasi berat basah pasca panen cabai rawit (Capsicum frutencens $L$.) karena tingginya kadar air yang terserap oleh tanaman cabai rawit (Capsicum frutencens $L$.) sehingga produk yang diperoleh akan cepat membusuk.

\section{SARAN}

1. Hasil penelitian ini dapat dijadikan sebagai referensi bagi petani cabai rawit (Capsicum frutencens L.) untuk 
mendapatkan kualitas produksi tanaman cabai rawit (Capsicum frutencens L.) terbaik dengan pemberian variasi nutrisi organik cair yang berasal dari limbah ikan, sedangkan pemberian nutrisi organik cair yang berasal dari limbah kulit pisang tidak dianjurkan karena hasil panen yang diperoleh mengandung kadar air yang tinggi sehingga

\section{DAFTAR PUSTAKA}

Anonim. 2015. Segudang Manfaat dan Kandungan Gizi Ikan Nila bagi Kesehatan. http://www.seputarikan.com/2 015/03/segudang-manfaatdan-kandungan-gizi.html. Tanggal akses 19 November 2016.

Ari Akbar Devananta. 2013. Potensi

Limbah Ikan sebagai Energi Alternatif yang Menjanjikan. http://berandainovasi.com/pot ensi-limbah-ikan-sebagaienergi-alternatif-yangmenjanjikan/. Tanggal akses 27 Agustus 2016.

Arifin, Z. 1996. Azolla : Pembudidayaan dan

Pemanfaatan Pada Tanaman Padi. Jakarta: Penebar Swadaya. Hlm 11.

Cahyono, B. 2003. Teknik Budidaya Cabai rawit dan Analisis Usaha Tani. Yogyakarta: Yogyakarta. Ditjen Perikanan Budidaya, Artikel.dkp.go.id.

Zahroh, Fatimatuz. 2015. Perbandingan Variasi mempercepat proses pembusukan hasil panen dan merugikan petani.

2. Dengan banyaknya manfaat yang terkandung dalam tanaman cabai rawit (Capsicum frutencens $L$.) maka diharapkan masyarakat mampu mengembangkan budidaya tanaman cabai rawit (Capsicum frutencens L.) di Indonesia.

Konsentrasi Pupuk Organik Cair dari Limbah Ikan Terhadap Pertumbuhan Tanaman Cabai Merah (Capsicum annum L.) (Skripsi). Semarang: Program Studi Pendidikan Biologi. Fakultas Ilmu Tarbiyah dan Keguruan. Semarang. Universitas Islam Negeri Walisongo.

Hadisuwito, S. 2007. Membuat Pupuk Kompos Cair. Jakarta: AgromediaPustaka.

Hanum Farida, Tarigan Martha dkk. 2012. Ekstraksi Pektin Dari Kulit Buah Pisang Kepok (Musa paradisiaca). Jurnal Teknik Kimia USU. Sumatera Utara: Universitas Sumatera Utara.

Harpenas, Asep \& R. Dermawan. 2010. Budidaya Cabai Unggul. Jakarta: Penerbit Swadaya.

Ilyas. 2014. Pupuk Organik Cair. Samarinda: Universitas Mulawarman. Paper. Hlm 34. Indarmawan, Taufik., A. Shofy 
Mubarak, dan Gunanti

Mahasri. 2012. Pengaruh Konsentrasi Pupuk Azolla

Pinnata terhadap Populasi

Chaetoceros sp. Marine and

Coastal Science, 1(1):61-70.

Kumarasinghe, K.S and D.L.

Eskew. 1993. Isotopic

Studies of Azolla and

Nitrogen Fertilization of

Rice. Netherlands: Kluwer

Academic Publishers. Hlm

87-102.

Kusandriani, Yenni dan Agus

Muharam. 2005. Produksi

Benih Cabai, E-book.

Bandung: Balai Penelitian

Tanaman Sayuran.

Prajnanta, F. 1999. Mengatasi

Permasalahan Bertanam

Cabai. Cetakan ke 4.

Jakarta: Penebar Swadaya.

Redaksi Agromedia. 2007.

Petunjuk Pemupukan.

Jakarta: PT. Agromedia

Pustaka. Redaksi Trubus. My

Potensial Business Cabai.

Depok: PT. Trubus Swadaya..

Rengi, Pareng dan Sumarto. 2011.

Kajian

Teknologi

Pemanfaatan Hasil Samping

Perikanan Untuk Pembuatan

Pupuk Cair Organik. Jurnal

Pusat Penelitian Lingkungan

Hidup Universitas Riau.
River, L; E. Aspe; M. Roeckel dan

M. C. Marti. 1998.

Evaluation of

Cleantechnology Process in

The Marin Product

Processing Industry. J.

Chem. Technol. Biotechnol. Hlm 73, 217-226.

Setiadi. 2002. Bertanam Cabai di Lahan dan Pot. Jakarta: Penebar Swadaya. hlm. 2834.

Soeryoko, Hery. 2011. Kiat Pintar Memproduksi Cair dengan PenguraiBuatan Sendiri. Yogyakarta: Lily Publisher.

Suryati, Teti. 2014. Bebas Sampah dari Rumah. Jakarta: PT. AgroMedia Pustaka.

Sutanto, R. 2002. Penerapan Pertanian Organik Yogyakarta: Kanisius. Hlm 206.

Tjitrosoepomo, Gembong. 2005.

Taksonomi Tumbuhan ObatObatan. Yogyakarta: Gadjah Mada University Press,

Trubus. 2011. Bertanam Cabai. Ungaran: Trubus Agri Widya.

Warisno. K. D. 2010. Peluang Usaha dan Budidaya Cabai. Jakarta: PT. Gramedia Pustaka Utama. 